\title{
Direct Evidence for Functional and Metabolic Differences between Dark and Ordinary Muscles in Free-swimming Yellowtail, Seriola quinqueradiata
}

\author{
Katsumi Tsukamoto* \\ (Received January 6, 1981)
}

\begin{abstract}
In order to correlate function of dark and ordinary muscles directly with metabolic activity by measuring the electrical activity and changes in blood lactate concentration simultaneously in freeswimming yellowtail in the water tunnel, a polyethylene cannula for blood sampling and three pairs of electrodes for electromyography were implanted in each fish weighing $600-900 \mathrm{~g}$.

Ordinary muscle showed electrical activity only during vigorous swimming at high speed, when no more than $10 \mathrm{~min}$ swimming caused a sharp increase in blood lactate concentration. On the other hand, in the recordings from dark muscle, relatively rhythmical burst of discharge was observed corresponding to each tail beat at any swimming speed. During moderate swimming at low speed when only dark muscle was active, there was no change in blood lactate concentration, even though the fish was forced to swim for 1-3 h.

Therefore, the accumulation of lactate does not seem to be caused by dark muscle activity, but caused by ordinary muscle activity. During burst or vigorous movement, energy seems to be supplied largely from anaerobic metabolism in ordinary muscle and during cruising or moderate swimming from aerobic metabolism in dark muscle.
\end{abstract}

Lateral muscles of most fishes are separated into two types; dark or red muscle consisting of slow fibers and ordinary or white muscle of fast fibers ${ }^{13}$. Based on physiological studies using electromyography ${ }^{2-\theta)}$, it is now generally agreed that the superficial slow fibers (dark muscle) are utilized by the fish for sustained slow-speed swimming or cruising, and the deeper fast fibers (ordinary muscle) for bursts of higher speed ${ }^{2}$. On the other hand, it is suggested by biochemical as well as histological studies ${ }^{y \sim 10}$ that dark muscle operates by aerobic glycolysis and lypolysis, and ordinary muscle by anaerobic glycolysis. The present study was undertaken to correlate function of these two types of muscles directly with metabolic activity by measuring the electrical activities and changes in blood lactate concentration simultaneously in free-swimming yellowtail.

\section{Materials and Methods}

Healthy specimens of the yellowtail, Seriola quinqueradiata, weighing 600-900 g were purchased from a fish farm in winter and reared with commercial feed for about 4 weeks before use in an outdoor tank (12t) with running seawater at
Fisheries Laboratory, Faculty of Agriculture, The University of Tokyo, in Shizuoka Pref. Rearing temperature ranged from 13 to $16^{\circ} \mathrm{C}$. Under anaesthesia with MS 222 (75 ppm), a polyethylene cannula for blood sampling and three pairs of electrodes for electromyography were implanted in the fish. The tip of the cannula (PE 60, Clay-Adams) was slipped over the cut end of a $21 \mathrm{G}$ disposable hypodermic needle from which the hub had been removed. The needle was bent $90^{\circ}$ at $2.2 \mathrm{~cm}$ from the tip. The cannula was filled with saline-heparin solution and inserted into the bulbus arteriosus from the ventral side and fixed with the sutures to the fish's body slightly anterior to the base of the pelvic fin. The electrodes were made of slender enamel-insulated copper wire ( $0.1 \mathrm{~mm}$ in diameter) with $2 \mathrm{~mm}$ barb at a tip. A length of $1 \mathrm{~mm}$ of wire above the barb was exposed to serve as an electrode for bipolar leads. They were implanted into three different regions of lateral muscle; superficial dark muscle, dorsal and ventral ordinary muscles, to the same depth of about $1 \mathrm{~cm}$ from the surface of the body. The cannula and electrode leads were bundled together and fixed at the base of the second dorsal fin in order to minimize the

* Ocean Research Institute, University of Tokyo, Minamidai, Nakano-ku, Tokyo 164, Japan

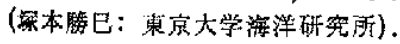


mechanical influence of the current and the body movement. After the operation, the fish was transferred to a water tunnel ${ }^{11}$, and kept for a minimum of $24 \mathrm{~h}$ until it swam constantly against the current of $24 \mathrm{~cm} / \mathrm{s}$. The water temperature in the tunnel was kept at $15 \pm 0.3^{\circ} \mathrm{C}$ during the acclimation and experiment. Following the acclimation period, the fish was subjected to $10 \mathrm{~min}-3 \mathrm{~h}$ periods of swimming at three test velocities, 49, 62 and $74 \mathrm{~cm} / \mathrm{s}$. Blood samples of $0.7 \mathrm{~m} /$ were taken at intervals from the cannula with a $1 \mathrm{~m} l$ hypodermic syringe for blood lactate measurement. Blood lactate was measured enzymatically by a slightly modified method of Scholz et al. ${ }^{12}$. Electromyograms of lateral muscles were recorded continually with a 4-ch mirror oscilloscope (Visigraph-5L, San-ei-sokki).

\section{Results and Discussions}

Five fish were successfully cannulated for re- peated blood sampling for 2-4 days. Typical examples of electromyographical records and changes in blood lactate level are shown in Figs. 1 and 2 , In the recordings from superficial dark muscle, relatively rhythmical burst of discharge was observed corresponding to each tail beat. Frequency and maximum amplitude of bursts of discharge increased as the velocity increased. No electrical activity could be detected in the recordings from dorsal and ventral ordinary muscles at the test velocity of $49 \mathrm{~cm} / \mathrm{s}$, whereas irregular bursts of discharge were observed at 62 and $74 \mathrm{~cm} / \mathrm{s}$. Therefore, only dark muscle seems to play the role of power supply during moderate swimming at low speed $(49 \mathrm{~cm} / \mathrm{s})$, and at higher speed $(62$ and $74 \mathrm{~cm} / \mathrm{s}$ ) ordinary muscle seems to be recruited to meet increased power demand. These electromyographical data are in good accord with those obtained in tuna ${ }^{3)}$ and rainbow trout ${ }^{4)}$.

Although blood lactate concentration was as high as about $100 \mathrm{mg} / \mathrm{d} l$ immediately after the

\section{Current velocity $(\mathrm{cm} / \mathrm{s})$}

49

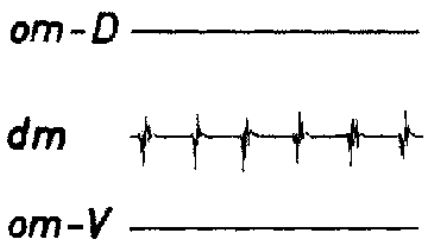

62

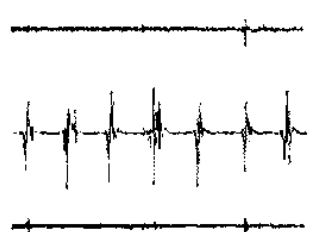

74

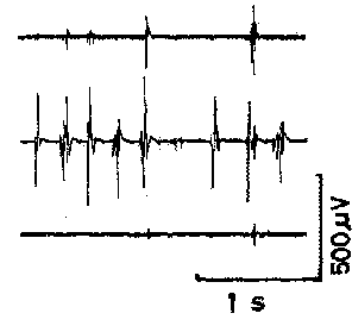

Fig. 1. Typical electromyographical recordings taken from the lateral muscles of the yellowtail, $765 \mathrm{~g}$ in body weight and $35.8 \mathrm{~cm}$ in folk length, swimming at three test velocities of 49,62 and $74 \mathrm{~cm} / \mathrm{s}$. d $d m$; dark muscle, om $D$ and $o m-V$; dorsal and ventral ordinary muscle, respectively. Time constant; $0.001 \mathrm{~s}$. At 62 and $74 \mathrm{~cm} / \mathrm{s}$, electrical activities were observed in not only $d m$ but also $o m-D$ and $o m-V$.

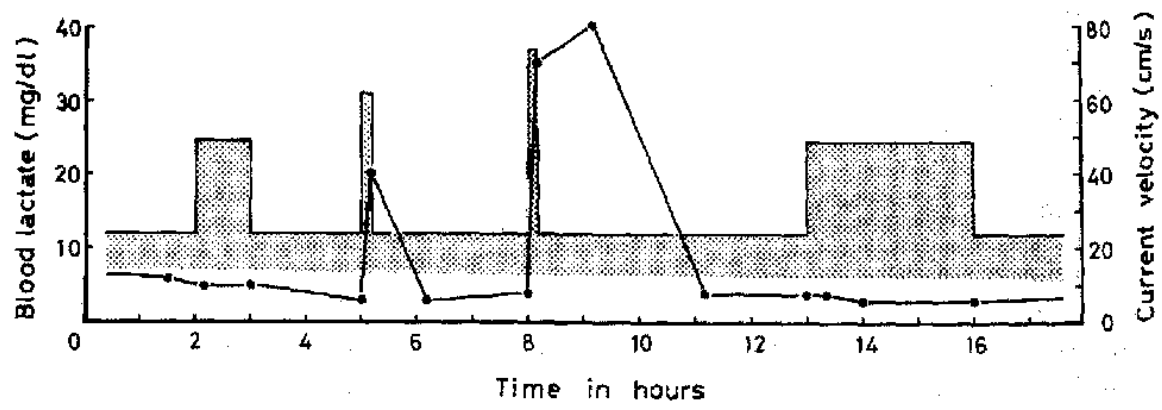

Fig. 2. Changes in blood lactate level of the yellowtail accompanying swimming activity at various velocities (stippled). Data in Figs. 1 and 2 were taken from the same fish. Zero hour in this figure is $40 \mathrm{~h}$ after the cannulation and electrode insertion. 
operation, it decreased to resting level of $3-12 \mathrm{mg} /$ $\mathrm{d} l$ after $24 \mathrm{~h}$. At the velocity of $49 \mathrm{~cm} / \mathrm{s}$ there was no change in blood lactate concentration, even though the fish was forced to swim for 1-3 h. On the other hand, swimming for $10 \mathrm{~min}$ at $62 \mathrm{~cm} / \mathrm{s}$ caused a sharp increase in blood lactate concentration to about $20 \mathrm{mg} / \mathrm{d} l$ and to $45 \mathrm{mg} / \mathrm{d} l$ at 74 $\mathrm{cm} / \mathrm{s}$. In comparison with electromyographical data, therefore, the accumulation of lactate does not seem to be caused by dark muscle activity, but caused by ordinary muscle activity, although we cannot exclude the possibility that dark muscle also produces lactate. In the present study, electrical activity of dark muscle increased linearly with the increasing velocity, whereas the blood lactate level showed a sudden change between 49 and $62 \mathrm{~cm} / \mathrm{s}$. Therefore, it seems to be reasonable to consider that dark muscle is not involved in the sharp increase in blood lactate concentration after vigorous movement. Furthermore, it has been reported in dogfish that the glycogen level in the slow fiber (dark muscle) does not change after a period of vigorous movement ${ }^{2}$.

In rainbow trout, DriedzIc and KicENIUK ${ }^{\text {a) }}$ also found no increase in blood lactate concentration during swimming at any velocities lower than critical velocity which was calculated using the empirical formula of BRETT' ${ }^{18)}$. As is shown in this experiment, critical velocity for yellowtail is likely to exist between 49 and $62 \mathrm{~cm} / \mathrm{s}$. At higher than critical velocity, energy is supplied largely from anaerobic metabolism in ordinary muscle and at lower velocity from aerobic metabolism in dark muscle. Thus, critical velocity is to be defined as the maximum velocity when no lactate is accumulated, or when dark muscle is active and ordinary muscle inactive. Only a little over critical velocity, lactate accumulation occurs suddenly to produce fatigue. Therefore, critical velocity would be an important turning point in exercise physiology of fishes.

\section{Acknowledgements}

I thank Dr. T. HrRano, Ocean Research Institute, The University of Tokyo, for critical reading of the manuscript. This research was partly supported by a research fund granted by The Ministry of Education, Science and Culture, Japan.

\section{References}

1) Q. Bone: in "Fish Physiology" (ed. by W. S. HOAR and D. J. Randal. ), Vol. 7, Academic Press, New York, 1978, pp. 361-424.

2) Q. BONE: J. mar. biol. Ass. U.K., 46, 321-349 (1966).

3) M. D. RAYNer and M. J. KeEnAN: Nature, 214, 392-393 (1967).

4) R. C. L. Hudsow: J. Exp. Biol, 58, 509-522 (1973).

5) M. Grefr-Walker and G. A. PUll: Comp. Biochem. Physial., A, 44, 495-501 (1973).

6) Q. BONE, J. KICENIUK, and D. R. JONES: Fish. Bull., 76, 691-699 (1978).

7) E. Bilnskr: in "Biochemical and Biophysical Perspectives in Marine Biology" (ed. by D.C. Malins and J.R. SARoENT), Vol. 1, Academic Press, New York, 1974, pp. 239-288.

8) W. R, DriedzIC and J. W. KICENTUK: J. Fish. Res. Board Can., 33, 173-176 (1976).

9) I. A. Johnston: J. Fish Biol., 11, 575-588 (1977).

10) I. A. Johnston, W. Davison, and G. Goldspinix: J. Comp. Physiol, 114, 203-216 (1977).

11) I. Hanyu, K. TSUKamoto, K. Yamakori, P. V. NGaN, K. Furukawa, and T. HrbiYA: Bull. Japan. Soc, Sci. Fish., 45, 1261-1265 (1979).

12) R. SCHOLZ, H. SCHMTZ, T. BuCHER, and J. 0. LAMPEN: Biochem. Z., 331, 71 (1959).

13) I. R. BRETt：J. Fish. Res. Board Can., 21, 11831226 (1964). 